\title{
Two Alternative Strategies for Raising Public Awareness of Science and Technology
}

\author{
http://dx.doi.org/10.3991/ijep.v3i4.2870 \\ J.C. Marques ${ }^{1}$, M.T. Restivo ${ }^{1,2}$, D. Sousa ${ }^{1}$, R. Pires ${ }^{1}$, C. Oliveira ${ }^{1}$ and R. Delgado ${ }^{1}$ \\ ${ }^{1}$ Universidade do Porto, Porto, Portugal \\ 2 IDMEC-PoloFEUP, Universidade do Porto, Porto, Portugal
}

\begin{abstract}
In today's knowledge society it is important to keep people informed about emerging technological developments while at the same time providing an accurate scientific and historical framework for such novelties in order to contribute to eradicate existing misconceptions. Dissemination of science and technology is presently essential to convey information within the research communities as well as among the younger generations and the general public. This paper describes two initiatives which pursue this objective by using multimedia tools. One consists in a set of 250 one-minute programs about engineering topics which were broadcast on $\mathrm{TV}$, radio and the multimedia online platform of a daily journal. The other is a collection of videos produced by a research unit in two alternative formats aimed at specialist and general viewers. Both initiatives, based on two very different budgets, may be instrumental for improving the general perception of the role of engineering and for attracting new vocations. The multimedia contents developed are also valuable teaching tools.
\end{abstract}

Index Terms-Dissemination, multimedia, science, technology.

\section{INTRODUCTION}

"Most of the fundamental ideas of science are essentially simple, and may, as a rule, be expressed in a language comprehensible to everyone" [1]. These wise words of Einstein and Infeld remain as accurate today as when they were written in 1938. What has radically changed in the meantime is the range and power of the media available for expressing the simple ideas of science and for conveying them with maximum impact to the citizens of today's knowledge society, as well as the increasing diversity of the institutions and organizations which are actively engaged in promoting public awareness of science and technology [2].

The idea that scientific knowledge is distant and inaccessible is being daily challenged and the interaction with society for contributing to the public understanding of science has actually been acknowledged as one of the main issues pertaining to the so called "Third Mission" of Universities [3].

While teaching and research were traditionally accepted as the two main missions, the importance of the involvement of University with society has been gaining increasing recognition, as is shown by E3M, a recent European initiative to define a set of indicators to evaluate and compare third mission accomplishments [4]. E3M (European Indicators and Ranking Methodology for University Third Mission) is a 3-year project co-funded by the European Commission under its Lifelong Learning Programme and developed by partners from eight European countries, whose aim is to generate a comprehensive instrument to identify, measure, and compare Third Mission activities of Higher Education Institutions from a wide perspective, by creating indicators on Third Mission activities and by giving a new approach on the concept of ranking methodologies [5].

The Faculty of Engineering, University of Porto (FEUP) and its Research Institutes have led several initiatives with the specific purpose of promoting the diffusion and circulation of scientific knowledge, employing various alternative strategies that take advantage of the diversity of multimedia tools and channels currently available.

In 2003-2005, Project EMPE (Exploration of Multidisciplinary Problems in Engineering) has congregated the collaboration of colleagues and students from various FEUP Departments in the exploration of multidisciplinary problems in engineering. Later some of the project topics have been adapted and a web page created for dissemination geared towards high school students [6].

In 2012 the experiment@portugal website has been developed to disseminate the national consortium for diffusion of online experimentation. The website houses video clips that document some of the consortium resources available [7]. It has received the 2012 IELA ELearning Honorable Mention [8].

In this paper reference will be made to two other initiatives: "Engenharia Num Minuto" (Engineering in One Minute) and Video Clips for R\&D\&I Dissemination. They are quite different in terms of budget, strategy, scope and target public, as well as in what concerns the multimedia tools employed. But both show the commitment of FEUP and its Research Institutes for outreach and engagement activities in the pursuit of fulfilment of its third mission.

\section{ENGINEERING IN ONE MINUTE}

"Engenharia Num Minuto" is a project conceived and developed at FEUP for the dissemination of science and technology amidst the general public through various media channels.

Its main focus has been the treatment of engineering related multidisciplinary questions which have been selected taking into account their current or historical relevance, their innovative or topical nature, as well as their interest for the man in the street. 


\section{A. Project Structure}

The project comprised a set of 250 one-minute thematic programs, each of which addresses one question related to the various engineering fields. In this way a very wide range of topics have been covered that highlight and explain the ubiquitous footprint left by engineering in many products, innovations, technologies and processes surrounding us in our daily life or which have become part of our history.

The production of the 250 programs has been made with the participation of 165 teachers and researchers from the nine Engineering Faculty Departments (Civil, Electrical, Mechanical, Chemistry, Informatics, Metallurgy and Materials, Industrial Management, Physics and Mining) and from the 10 Research Institutes housed at the FEUP campus.

The 250 spots have been primarily developed for television and subsequently adapted for radio and ciberjournalism diffusion. For the video version the spoken text had a limit of 800 characters, an exacting exercise in conciseness. This was complemented by the display of a final statement of 70 to 80 characters highlighting a curious angle of the topic addressed. The recording sessions have been a novel and very enriching experience for the 165 participating authors, many of whom were definitely more used to perform in front of a live audience.

The logo and the visual image of the programs have been carefully conceived (Fig. 1). The jingle of "Engenharia num Minuto", included in the title sequence, has been composed by Virtus, a Portuguese hip-hop musician. Both the title and the closing sequences have been developed by nFactos [12], the producer. Each spot is preceded by a brief introduction made by one of the team journalists (DS) with the purpose of raising the public curiosity about the topic.

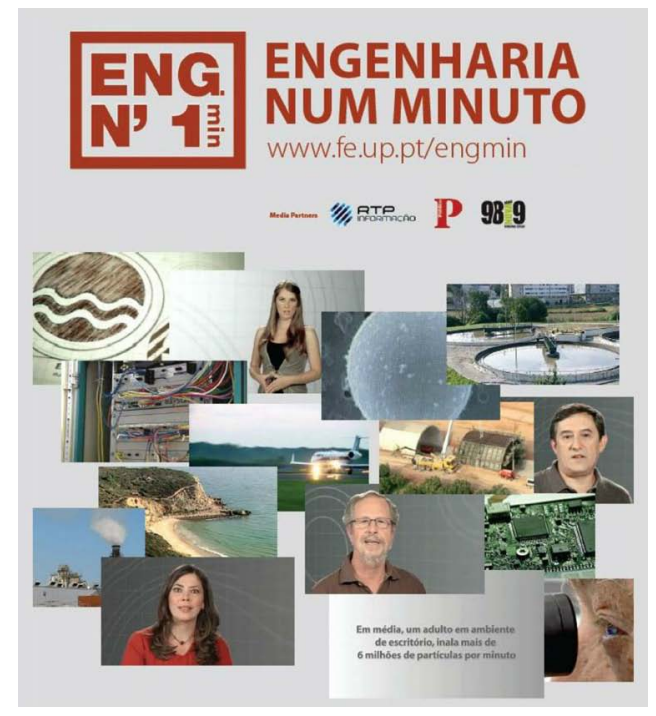

Figure 1. Logo and sample images from various programs.

The abundant use of graphics, photos and video clips, together with simple and clear sentences, deliberately devoid of technical jargon but without compromising accuracy, were the main ingredients for giving coherence and fluidity to the final product in order to make it attractive to a non-specialist public, wide ranging in both age and social status.
The 250 video and audio clips have been broadcast during 50 weeks starting in November 2011, with the support of three media partners: one national television channel ("RTP Informação") [9], one radio station ("Rádio Nova") [10] and the online platform of one national daily newspaper ("Público") [11]. In addition to Monday to Friday broadcast of a one-minute video, a 5day compact was available at the weekend. The complete set can also be found at the project website, http://www.fe.up.pt/engmin/.

An illustrative sample of 50 of the 250 issues explored is now listed.

- How are earthquakes generated?

- What is inclusive design?

- What is the carbon footprint?

- What are composite materials?

- How does the internet work?

- What problems are caused by high speed trains?

- How does an electric guitar work?

- How can we produce electricity in our homes?

- What is nanomedicine?

- How does e-mail work?

- How do mobile phone companies know where we are?

- How does the speed radar work?

- What are nanomaterials?

- What is the use of LEGO in engineering teaching?

- How do bar codes work?

- Is it possible to prevent rising damp in old stone masonry building walls?

- What is the QR code?

- What is the origin of the QWERTY keyboard?

- What is a wiki?

- How can masonry buildings withstand earthquakes?

- What are stem cells?

- What are noise maps for?

- How is the word "bug" related to computers?

- How were gothic cathedrals designed and built?

- How does a fuel cell work?

- What is biomimetics?

- How does GPS work?

- How are CAT scans made?

- How can engineering help sport?

- How do dental implants work?

- How can biomaterials help tissue regeneration?

- Have you heard about paper transistors?

- How do LED light bulbs work?

- How to prevent condensation and mould in our home?

- How do facial recognition systems work?

- What are structural adhesives for?

- What is the World Wide Web?

- What is the railway track gauge for?

- What is rapid prototyping?

- How does a tunnel boring machine work?

- What is a compiler?

- How do spam filters work?

- What do peacock feathers and optical fibers have in common?

- How can engineering detect voice problems and improve singing?

- How to choose a light bulb?

- How do wind turbines work?

- How can temperature be visualized?

- Why do landslides occur?

- Do you know what a supply chain is?

- How does car ABS work? 
The script of two of the programs, respectively authored by RD and JCM, is now included for illustration of the demanding balance required between conciseness, clarity and content.

\section{B. How Are Earthquakes Generated?}

Our planet is predominantly fluid, with a diameter of $12,000 \mathrm{~km}$, only a few dozen of which are solid (from 10 to $80 \mathrm{~km}$ ). This solid crust is fractured into large plates that move relative to each other a few $\mathrm{mm}$ per year, as if floating on the liquid interior.

These movements produce inter-plate compressions that after a few years may cause a localized failure which originates a sudden relative motion.

The neighbouring zone is shaken by an explosion-like action. The violence of the earthquake depends on the energy released in the process (measured by the Richter scale) and attenuates as the distance from the epicentre increases, local effects being measured by the Mercalli scale.

And it is this motion that propagates upwards to the earth surface, rocking the foundations of the buildings and causing their whole structure to oscillate, as happens when we are on top of a platform that suddenly starts to move.

The major objective of seismic engineering is to make sure that the structures are able to survive the earthquake motion which is likely to occur on each location without experiencing catastrophic failure, as is unfortunately so often reported by the media.

FACT - "The most violent earthquake has been registered in Valdivia (Chile) in 1960."

\section{Why Do Landslides Occur?}

Landslides often make the headlines particularly when their consequences are serious in terms of casualties or property damage.

The impact of these phenomena is very impressive in many cases given the large volume of material mobilized, the enormous dimension of the area affected and the sensation of complete impotence felt by the people due to the magnitude of the forces involved.

Several natural factors may contribute to trigger a landslide, such as a long period of heavy rain or the occurrence of an earthquake.

Natural slopes may also be destabilized by human intervention as is the case when unsupported excavation is carried out at the toe of the slope or when heavy loads are applied near the top of the slope.

FACT - "A landslide caused by the 1949 earthquake in Tajikistan killed 28000 people."

\section{Project Management and Financial Support}

The Project team tasks have included scientific coordination (RD and JCM), administrative management (CO and RP) and journalistic advisory and production (RP and DS).

The Project has been supported by the "Media Ciência" Program launched by "Ciência Viva", the National Agency for Scientific and Technological Culture, with funding from COMPETE (a Competitiveness Factors Operational Programme within QREN, the 2007-2013 Portuguese National Strategic Reference Framework) and the Ministry of Education.

\section{E. Further Developments}

Engenharia Num Minuto" has been shortlisted for the 2013 European Science TV and New Media Festival Awards under the New Media Productions category [13]. Public screenings will take place at the Science Gallery in Dublin (June 14-16), where the awards will be decided. Award presentation will take place in November, at the Ciência Viva Science Centre in Lisbon.

Work has now started on a follow-up to the "Engenharia Num Minuto" Project in the form of a book containing an extended and adapted version of the text of a number of selected programs, with an enclosed DVD offering the complete set of 250 one-minute videos.

\section{VIDEO CLIPS FOR R\&D\&I DISSEMINATION}

Advances in science and technology in the last decades have changed the communication process contributing for improving the academic skills in communicating techno sciences. The effectiveness of this communication depends on the understanding level of the target. Consequently dissemination of R\&D\&I activities must follow principles of communication science by differentiating messages according to goals and to target audiences. Therefore it is important to define who is the receiver, how to speak his/her language, how to stimulate his/her curiosity and how to listen to others. And, finally, it is important to define the broadcast media type.

Video, a multi-sensorial communication tool, is a very powerful method for communicating information and it is particularly efficient for conveying complex scientific ideas by its inherent capacity for catching and keeping the viewer attention with colour images in motion and an adequate sound track for reinforcing the message. On the other hand a camera is also able to record unique events, impossible to reproduce once more in other moments and places. Video is a fantastic way of "bringing the scientific process to life" [14]. But the honesty and integrity of its authors, the reliability and robustness of recording methods, and its communication efficiency are factors of paramount significance.

Sharing online video represents a powerful way to connect with large communities and has become an important tool for science dissemination.

In 2008 an initiative started within the System Integration and Process Automation Research Unit (http://uispa.pt/) aimed at the production of video clips for dissemination of R\&D\&I tasks oriented towards two main target audiences: the academic community and the general public. By integrating video clips within the UISPA web site, rather than merely using short abstracts, the research unit became more open about its activities to the academic community.

An illustrative example of this strategy can be appreciated by clicking on the video and photo icons located next to the "see details" message in the LipoTool section included in the UISPA web page and available at http://paginas.fe.up.pt/wwwidmec/uispa/sensors actuators.php

Simultaneously, UISPA decided to produce an alternative, simpler version of these clips in order to make the same content also available for the public in general. Those contents have been used at University of Porto events of public nature, such as the Annual Exhibition and Open Days. 
In both cases the clips were short (meaning less than two minutes long), small in bytes (to be easily uploaded from the internet while offering a good balance between quality and size), and including concise information. The idea was to provide just enough detail to trigger the viewer curiosity, thereby inducing the need for further exploration.

The main aim was to demonstrate that this double goal could be achieved at very low cost. So, an exercise was undertaken involving the production of two alternative versions of each video clip made from the same collected material but differing in the degree of technical detail, which was greater for the specialist end and less pronounced for general dissemination. For that purpose a small camera was used (Panasonic SDR-H80), without special ambient lighting or sound recording requisites and using current video edition tools. It was decided to use subtitles and professional voice-over, given the academics natural inability to be excellent communicators. The subtitles are as short as possible, just enough to pass the main message. If costs have to be further reduced the option is to use only subtitles and music.

Academics often share a curious trait - they are always enthusiastic in promoting new research developments and/or innovative achievements and end up doing written reports of results and techno-scientific publications. However, they usually do not care about producing abridged versions of their work in a lighter format adequate for future dissemination of their achievements, either at academia level or for general public information. One of our goals has been to demonstrate that it is possible to make good use of archive material for giving a new life to equipment, materials or items no longer in use.

Two illustrative examples of the video clip development activity are now described. In both cases the academic and general public versions have been prepared.

The first topic deals with the development of a new Skinfold Calliper, a novel device with unique characteristics for use in health care environments. This device permits the estimation of the percentage of body fat which is relevant given the current overweight and obesity problems in the civilized world that lead to many types of serious diseases. Due to this the video clip starts by highlighting examples of junk food and also uses images of health problems to introduce the background context of the new Skinfold Calliper (Fig. 2).

The second topic concerns an autonomous sailboat including all related aspects, from its building process up

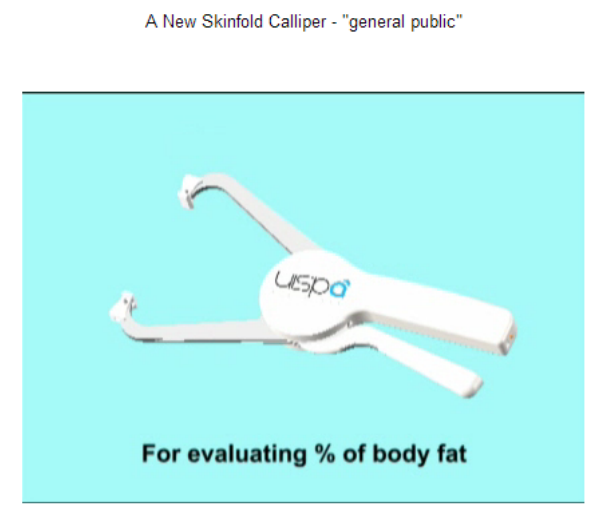

Figure 2. A New Skinfold Calliper.
FASt - FEUP Autonomous Sailboat - "general public"

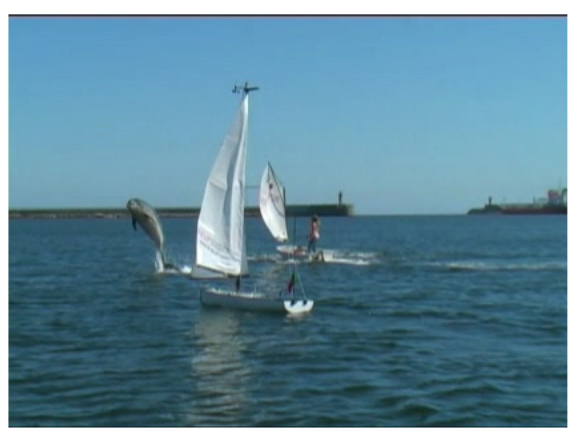

Figure 3. FASt - FEUP Autonomous Sailboat.

to its sensorization and complex control involving electronics and software algorithms. Sport and leisure aspects are integrated in the video clip in order to make the topic attractive. All the used materials have been recovered from the sailboat builder personal archive given that the item is presently a museum object, Fig. 3, (FASt FEUP Autonomous Sailboat).

Final results of both clip videos, oriented for both target publics, are available and can be compared at the address http://paginas.fe.up.pt/ mm09049/tese/en.html.

A survey has been carried out in order to evaluate the outcome. This survey aimed to assess satisfaction, interest, quality and effectiveness of those video clips. Its ten questions were structured in several dimensions for measuring different parameters. The general public was represented by a sample of 135 individuals with different age and education levels. The academics sample comprised 107 individuals, also with a wide range of age and education level (degree, MSc and $\mathrm{PhD}$ ).

The data analysis was made in the context of a master thesis in multimedia technology [16].

The survey was conducted looking to the two specific publics established as targets and using adequate samples. Final results analysis demonstrated very similar and positive conclusions coming from the two publics.

Considering the adequate profile of both samples a final convenience sample of 242 individuals can be also considered and, as an example, results from the question concerning the general evaluation of the video clips are presented and summarized in Fig. 4.

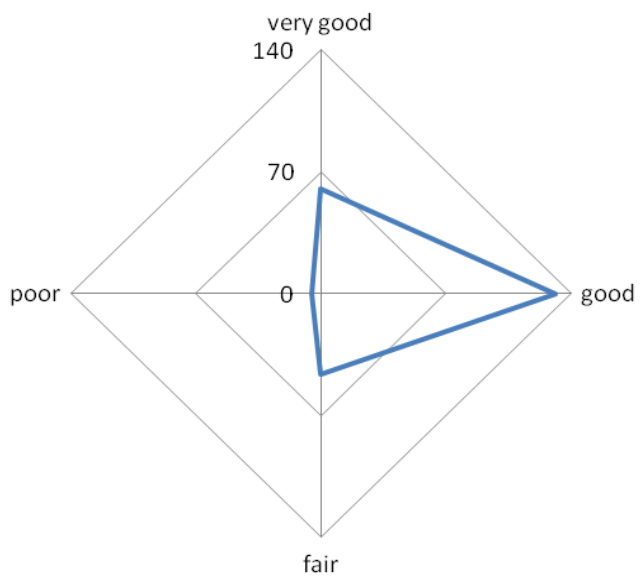

Figure 4. General evaluation of the video clips. 
This strategy derived from the experience of having to document the multiple activities carried out by UISPA team members in multidisciplinary involvements.

The UISPA web page is a repository of multimedia contents that illustrate in a suggestive way its activity which has namely led to the completion of a number of master theses $[15,16]$.

Finally it is important to report the cost estimation for producing two versions of each clip addressed at two distinct target groups, the specialist end and the general public. The estimation has considered equipment, digital edition tools and software, voice-over, room occupation and trained manpower. Initial costs and amortization rates were also considered. The final value came out at around $150 €$ per clip, a very reasonable number for such a powerful dissemination tool.

\section{FINAL REMARKS}

The two projects reported herein show a clear commitment of the Faculty of Engineering to promote public awareness of the pervasive presence of science and technology in all the aspects of human intervention.

It is expected that raising this awareness level can lead to a stronger support from public opinion to the importance of scientific literacy in all the areas and levels of education.

The two projects also show, on one hand that university teachers and scientific researchers need to develop advanced communication skills in order to accomplish the "third mission" effectively and, on the other hand, that science and technology video clips for dissemination purposes are a high impact tool with a surprisingly low cost and a quite substantial educational added value.

Finally, it should be mentioned that these dissemination contents are in themselves good tools for the learning activity of engineering students and for illustrating real applications of what they study. They also encourage students to invest in ending up their projects with a set of well-organized and also "suggestive" documentation. This trend has been recently observed at FEUP.

\section{REFERENCES}

[1] A. Einstein, and L. Infeld, The Evolution of Physics, Cambridge University Press, 1938.

[2] D. Sousa, "Communication of Science and Technology on TV Getting the Message Across Effectively," Master Thesis in Communication Sciences (in Portuguese), FLUP (in preparation).
[3] P. Laredo, "Toward a third mission for Universities," The third mission of Universities, UNESCO Workshop, 2007.

[4] A. Soeiro, "Defining and delivering the University's third mission," http://www.evolllution.com/program_planning/definingand-delivering-the-universitys-third-mission/

[5] http://www.e3mproject.eu/

[6] http://empe.fe.up.pt

[7] http://www.fe.up.pt/experimentaportugal

[8] http://www.ielassoc.org/awards_program/past_winners.html

[9] http://www.rtp.pt/programa/tv/p28498

[10] http://www.radionova.fm/podcasts/programa/31

[11] http://www.publico.pt/pesquisa?q $=\% 22$ engenharia + num + minuto $\% 22$

[12] www.nfactos.pt

[13] http://europaws.org/festival/2013-shortlist/ (accessed May 2013).

[14] M. Busse, "Online Video is transforming perceptions of science", New Scientis Tech, No. 2612, 11 July 2007.

[15] D. Fernandes, "Scientific Divulgation Using Video and Audio Through the Web," Master Thesis in Multimedia Technology (in Portuguese), FEUP, 2009.

[16] J. V. Quintela, "The Use of Video for Dissemination of R\&D\&I Activities," Master Thesis in Multimedia Technology (in Portuguese), FEUP, 2011.

\section{AUTHORS}

J. C. Marques is with Universidade do Porto, Faculdade de Engenharia, Porto, Portugal (e-mail: jmarques@fe.up.pt).

M. T. Restivo is with Universidade do Porto, Faculdade de Engenharia and with UISPA Research Unit at IDMEC-Pólo FEUP, Porto, Portugal (e-mail: trestivo@fe.up.pt).

D. Sousa is with Universidade do Porto, Faculdade de Engenharia, Porto, Portugal (e-mail: dsousa@fe.up.pt).

R. Pires is with Universidade do Porto, Faculdade de Engenharia, Porto, Portugal (e-mail: raquelp@fe.up.pt).

C. Oliveira is with Universidade do Porto, Faculdade de Engenharia, Porto, Portugal (e-mail: colive@fe.up.pt)

R. Delgado is with Universidade do Porto, Faculdade de Engenharia, Porto, Portugal (e-mail: rdelgado@fe.up.pt).

This article is an extended and modified version of a paper presented at the EDUCON2013 conference held at Technische Universität Berlin, Berlin, Germany from March 13-15, 2013. Submitted, January, 17, 2009. Published as resubmitted by the authors on May, 16, 2009. 